\title{
Ethnic differences in bladder cancer survival
}

\author{
David S. Yee ${ }^{a}$, Nicole M. Ishill ${ }^{b}$, William T. Lowrance ${ }^{a}$, Harry W. Herra ${ }^{a}$ and Elena B. Elkin ${ }^{b}$ \\ aUrology Service, Department of Surgery, Memorial Sloan-Kettering Cancer Center, New York, \\ New York, USA \\ ${ }^{b}$ Department of Epidemiology and Biostatistics, Memorial Sloan-Kettering Cancer Center, New \\ York, New York, USA
}

\begin{abstract}
Objectives-Racial disparities in bladder cancer outcomes have been documented with poorer survival observed among blacks. Bladder cancer outcomes in other ethnic minority groups are less well described. We examined trends in bladder cancer survival among whites, blacks, Hispanics, and Asian/Pacific Islanders in the US over a 30-year period.

Methods-From the Surveillance, Epidemiology and End Results cancer registry data, we identified patients diagnosed with transitional cell carcinoma of the bladder between 1975 and 2005. This cohort included 163,973 white, 7,731 black, 7,364 Hispanic and 5,934 Asian/Pacific Islander patients. We assessed the relationship between ethnicity and patient characteristics. Disease-specific 5-year survival was estimated for each ethnic group and for subgroups of stage and grade.
\end{abstract}

Results-Blacks presented with higher stage disease than whites, Hispanics and Asian/Pacific Islanders, although a trend toward earlier stage presentation was observed in all groups over time. Five-year disease-specific survival was consistently worse for blacks than for other ethnic groups, even when stratified by stage and grade. Five-year disease-specific survival was $82.8 \%$ in whites compared with $70.2 \%$ in blacks, $80.7 \%$ in Hispanics and $81.9 \%$ in Asian/Pacific Islanders. There was a persistent disease-specific survival disadvantage in black patients over time which was not seen in the other ethnic groups.

Conclusions-Ethnic disparities in bladder cancer survival persist between whites and blacks, while survival in other ethnic minority groups appears similar to that of whites. Further study of access to care, quality of care and treatment decision making among black patients is needed to better understand these disparities.

\section{Keywords}

ethnic groups; healthcare disparities; survival; urinary bladder; urinary bladder neoplasms

(C) 2011 Published by Elsevier Inc.

Corresponding Author: David S. Yee, MD, MPH, Urology Service, Department of Surgery, Memorial Sloan-Kettering Cancer Center, 1275 York Avenue, Box 27, New York, NY 10065, United States, Phone: +1-714-767-7227, Fax: +1-646-735-0032, yeed1@mskcc.org.

Publisher's Disclaimer: This is a PDF file of an unedited manuscript that has been accepted for publication. As a service to our customers we are providing this early version of the manuscript. The manuscript will undergo copyediting, typesetting, and review of the resulting proof before it is published in its final citable form. Please note that during the production process errors may be discovered which could affect the content, and all legal disclaimers that apply to the journal pertain. 


\section{INTRODUCTION}

Bladder cancer incidence and survival vary among ethnic groups. ${ }^{1-3}$ Prior studies demonstrate lower incidence and poorer survival in blacks compared with whites. ${ }^{4-6}$ Although much of the difference in survival has been attributed to higher stage at presentation in blacks, ${ }^{5,6}$ this disparity persists between whites and blacks with similar stage, grade and treatment. ${ }^{7}$ Research regarding bladder cancer outcomes in other ethnic groups, such as Hispanics and Asian/Pacific Islanders (APIs), is limited.

The objective of this study was to evaluate trends in bladder cancer presentation and disease-specific survival (DSS) in whites, blacks, Hispanics and APIs between 1975 and 2005. Given increased health care awareness, improved socioeconomic conditions and improved access to health care during this time period, we hypothesized that ethnic disparities in bladder cancer outcomes would decrease over time.

\section{MATERIALS AND METHODS}

\section{Data Source}

We used data from the Surveillance, Epidemiology and End Results (SEER) program, a consortium of population-based cancer registries sponsored by the National Cancer Institute. SEER collects information on patient and disease characteristics and first course of treatment, with active follow-up for vital status and cause of death (http://seer.cancer.gov). ${ }^{8}$ In 1975, SEER included the states of Connecticut, Iowa, New Mexico, Utah and Hawaii, the 13-county Seattle-Puget Sound area and the metropolitan areas of Atlanta, Detroit and San Francisco-Oakland. By 2001, the SEER Program had gradually expanded coverage to include California, New Jersey, Kentucky and Louisiana, as well as American Indians residing in Arizona, the Alaskan Native populations residing in Alaska and ten predominantly black rural counties in Georgia. ${ }^{8}$

The SEER areas currently cover more than $25 \%$ of the US population and include $23 \%$ of blacks, $40 \%$ of Hispanics, $42 \%$ of American Indians and Alaska Natives, 53\% of Asians and $70 \%$ of Hawaiian/Pacific Islanders. ${ }^{8}$ The SEER standard for case ascertainment is $98 \%$. To review the trends in bladder cancer over time, 5 -year intervals were established beginning in 1975. The most recent interval, 2000-2005, included 6 years of review.

\section{Study Cohort}

We identified all patients in SEER diagnosed with transitional cell carcinoma of the bladder (8120.2, 8120.3, 8121.2, 8122.3, 8130.2, 8130.3, 8131.2, 8131.3) between 1975 and 2005 whose race and stage at diagnosis were known. In SEER, race/ethnicity is determined from medical records and registration information for each individual.

\section{Disease-Specific Survival}

DSS was defined as the time from initial diagnosis to the time of death attributed to bladder cancer. SEER collects information on underlying cause of death from the state death certificate. $^{8}$

\section{Covariates}

In addition to race/ethnicity, we examined a number of patient and disease characteristics. In the absence of individual level data on socioeconomic status, we used the median household income in the census tract of residence. Urban vs rural residence was based on U.S. Census Bureau designations for these areas. Tumor stage was defined as localized for organconfined tumors, regional for tumors with extravesical extension or regional lymph nodes 
and distant for patients with visceral metastases or nodal involvement above the pelvic brim. Advanced stage was defined as regional- or distant-stage disease at presentation. Primary treatment, ascertained from SEER data on the first course of cancer-directed therapy, was categorized as surgery only, radiation therapy only, both or other. 'Other' treatment included strategies that did not involve surgery or radiation therapy, such as observation or systemic chemotherapy.

\section{Statistical Analysis}

Chi-square tests were used to evaluate unadjusted associations between race/ethnicity and other demographic and clinical characteristics. We used Poisson regression to determine whether there were differences across racial groups in the proportion of advanced-stage cases over the course of the study. Proportional hazards regression models were used to examine the relationship between disease-specific death and race/ethnicity, adjusting for sociodemographic and disease characteristics. Two-way interactions between ethnicity and other covariates were explored. All $P$-values were two-sided, and $P<.05$ was considered statistically significant. Statistical analyses were performed in SAS (version 9.1, Cary, NC).

\section{RESULTS}

\section{Cohort Characteristics}

We identified 163,973 white, 7,731 black, 7,364 Hispanic and 5,934 API patients diagnosed with bladder cancer in 1975-2005 (Table 1). There were 1,329 patients of other $(\mathrm{n}=381)$ or unknown $(\mathrm{n}=948)$ race/ethnicity who were excluded. Of the 185,002 patients in the study cohort, 55,964 (30\%) were younger than 65 years of age at the time of diagnosis. Black patients were less likely to be married $(47 \%)$ at the time of bladder cancer diagnosis compared with whites (65\%), Hispanics (62\%) and APIs (70\%).

Surgery was the predominant treatment modality among all ethnic groups. Radiation was used infrequently and when given, it was usually used in conjunction with surgical therapy. Although a trend toward increasing use of surgery alone was observed in all racial/ethnic groups over time, blacks were less likely to have surgery alone and more likely to receive radiotherapy than whites, Hispanics and APIs in each time period.

Blacks were more likely to present with advanced-stage disease (31\%) than whites (21\%), Hispanics $(24 \%)$ and APIs $(23 \%)(P<.001$ for comparisons of black vs white, black vs Hispanic and black vs API difference between 1975-1979 and 2000-2005).

Higher rates of poorly differentiated and undifferentiated grades at tumor presentation were observed in black (47\%) and API (46\%) patients compared to white (39\%) and Hispanic (40\%) patients $(P<.001$ for comparison of black vs white and black vs Hispanic in difference between 1975-1979 and 2000-2005). Over time, the percentage of patients with poorly differentiated or undifferentiated disease increased among all ethnic groups, particularly among Hispanics (27\% to $43 \%$ ), APIs (37\% to $49 \%$ ) and whites (33\% to $44 \%$ ).

\section{Survival}

With a median followup of 4.2 years (interquartile range $1.7-8.6$ years), blacks had poorer DSS than other ethnic groups (Fig. 1). DSS was similar for whites, Hispanics and APIs.

The survival disparity for black patients persisted within strata of disease stage and tumor grade (Table 2). The greatest racial disparities were observed among patients with local and regional stage disease and those with poorly differentiated and undifferentiated disease. For example, in those with regional disease, 5-year DSS was 50.3\% in whites compared with 
$41.5 \%$ in blacks - an absolute difference of $8.8 \%$. In those with poorly differentiated disease, 5-year DSS was $67.7 \%$ in whites compared with $51.9 \%$ in blacks - an absolute difference of $15.8 \%$. Examining cohorts of patients by time period of diagnosis, there was a persistent DSS disadvantage in black patients over time which was not seen in the other ethnic groups. However, DSS improved for all ethnic groups, with the greatest improvement for localized stage tumors in black patients (from $76.2 \%$ in $1975-1979$ to $85.9 \%$ in 2000 2005).

In multivariable analysis, black patients had a higher likelihood of disease-specific death, adjusting for age, gender, marital status, census tract median household income, urban residence, year of diagnosis, geographic area, pathologic stage and grade and treatment (Table 3). With the exception of urban residence, these covariates were also themselves significantly associated with disease-specific mortality. Cancer stage (hazard ratio [HR] 15.97; 95\% CI, $15.30-16.67 ; P<.0001$ ) and grade (HR 5.90; 95\% CI: $5.49-6.33, P<$. $001)$ were strong predictors of cancer-specific death.

\section{COMMENT}

Our study provides an initial description and highlights important differences in bladder cancer survival among multiple ethnic groups. In particular, Hispanics and APIs had similar DSS compared to whites. Historically research specific to the health of other minorities has been limited. ${ }^{9}$. A 2003 study showed that the federal government has scant data on the health of APIs and only $0.2 \%$ of federal grants from 1986 to 2000, involved API health directly or tangentially. ${ }^{10}$

Despite a modest improvement over time in DSS, we observed a persistent disparity for black patients with bladder cancer. Five-year DSS was consistently worse for blacks than for patients of other race/ethnicity, even when stratified by stage and grade and adjusted for other patient characteristics and primary therapy. These findings support a recent SEER study that reported an excess hazard of death from bladder cancer among blacks despite adjusting for age, stage and grade. ${ }^{11}$

Tumor stage at diagnosis is an independent predictor of bladder cancer survival. ${ }^{12,13}$ Although a stage disparity persists between blacks and other ethnic groups, the gap has narrowed somewhat over the last 30 years. Black patients today are more likely to present with localized disease than their historical counterparts. However, even in the most recent time period we evaluated, the $70 \%$ rate of localized disease in blacks was still less than the rate of $79 \%$ observed in whites.

A disparity in tumor grade was also observed in this cohort. In each time period, black and API patients presented with higher grade tumors than white patients. We also observed a trend toward increasing rates of poorly differentiated and undifferentiated disease among all ethnic groups. The etiology of this trend is unclear since the percentage of patients with unknown grade remained relatively stable and thus may not be attributable to improved pathology reporting.

A disparity between blacks and whites in 5-year DSS persisted even when comparing patients of similar stage and grade. The disparity was more marked in patients with localized and regional stage disease; poorer survival in these disease stages may reflect treatment delay during a critical period where curative therapy is possible. ${ }^{4}$ The smaller survival disparity between black and white patients with distant-stage bladder cancer likely reflects the poorer prognosis associated with metastatic bladder cancer. 
Marital status was also an independent predictor of DSS. Gore et al demonstrated that marriage was associated with improved survival in 7,262 patients treated with radical cystectomy for bladder cancer. ${ }^{14}$ Marital status has also been associated with cancer survival in other settings. ${ }^{15}$ The nearly $20 \%$ higher marriage rate in whites, Hispanics and APIs compared to blacks might contribute to improved survival through several mechanisms. A spouse may encourage more prompt evaluation of symptoms leading to an earlier diagnosis, provide psychosocial support, promote smoking cessation and advocate for care in higherquality facilities. ${ }^{14}$

Currently, no clear genetic differences or tumors with poor prognostic molecular markers have been identified that correlate with more aggressive bladder cancer in blacks. However, ethnic differences in tobacco use have been observed, which are associated with disparities in bladder cancer incidence and possibly survival. According to the 1999 - 2001 National Survey on Drug Use and Health, cigarette smoking was approximately $40 \%$ less common in adult APIs than in adult whites and blacks. ${ }^{16}$

Hispanics also had an approximately 50\% lower average annual prevalence of cigarette smoking than whites in the 1994 - 1996 National Health Interview Survey. ${ }^{17}$ A systematic review showed that smoking significantly alters patient prognosis after treatment for bladder carcinoma. ${ }^{18}$ Thus, lower smoking rates among Hispanics and APIs compared with blacks may in part explain their higher DSS.

Disproportionate application of treatments may also contribute to survival disparities between black and white patients. Previous studies have reported that blacks are more likely to receive radiation, ${ }^{19}$ radiation and chemotherapy ${ }^{20}$ or no treatment ${ }^{21}$ for bladder cancer compared to whites. We did not detect any ethnic disparities in the use of chemotherapy. Recently, Hollenbeck et al reported racial differences in initial treatment of early stage bladder cancer using SEER-Medicare data from 1992 through 2002. ${ }^{22}$ However, after the authors adjusted for these differences in initial treatment intensity and in the provider responsible for the bladder cancer care, the differences failed to account for the greater risk of death in black patients compared to white patients. ${ }^{22}$

In a cohort of Medicare beneficiaries, Schrag et al also demonstrated that a higher socioeconomic status was associated with a greater likelihood of cystectomy in patients with muscle-invasive bladder cancer. ${ }^{23}$ Recently, investigators have established an association between ethnicity and surgical outcomes after cystectomy, where black patients had greater mortality and longer hospitalization than did white patients undergoing cystectomy. ${ }^{24,25}$ These differences in outcomes may be associated with differences in hospital volume, as several studies have demonstrated lower mortality after cystectomy in high-volume hospitals. ${ }^{26,27}$ In a recent study, blacks were less likely to undergo cystectomy at a highvolume hospital, thereby placing them at a higher risk of postoperative complications. ${ }^{24}$ Race may also be a predictor of adherence to surveillance among patients with superficial bladder cancer. ${ }^{28}$ Compared with $17 \%$ of white patients, almost $30 \%$ of black patients and patients of other races had substandard follow-up.

Several limitations in our study should be acknowledged. The SEER program expanded in both size and geography during the study period, thus the racial/ethnic disparities we observed may reflect sociodemographic changes over time in the SEER registries. Racespecific bladder cancer incidence estimates have been stable over time in SEER. Use of SEER historic staging is a less precise alternative to tumor-node-metastasis pathological staging used in clinical decision making. However, the latter was not available for cases diagnosed prior to 1988 and the former sufficiently distinguished organ-confined from nonorgan-confined disease. Also, while we assessed variation in primary treatment and its 
relationship to both ethnicity and DSS, we had no information on subsequent cancerdirected therapy and the incidence and treatment of recurrent disease. Other potential confounders, such as surveillance after primary therapy, were not available for analysis.

An important limitation of the SEER database is the lack of information on patient comorbidity and hospital volume, factors that are associated with adverse outcomes following radical cystectomy and which may influence diagnosis and treatment. ${ }^{26,27,29}$ While this information may be supplemented by analyzing cases in the linked SEERMedicare database, that data source is limited to patients aged 65 years or older. Although bladder cancer is primarily considered a disease of the elderly, with the median age at diagnosis of transitional cell carcinoma being 69 years in males and 71 years in females, ${ }^{3}$ $30 \%$ of bladder cancer patients in our study were under age 65 .

A final limitation is the lack of patient-level measures of socioeconomic status, an important potential confounder because ethnicity may be a surrogate for socioeconomic status. ${ }^{30} \mathrm{In}$ our analysis, the bottom two quartiles of census tract median income were associated with a higher risk of cancer-specific death, suggesting that lower socioeconomic status also has a deleterious effect on survival outcomes.

\section{CONCLUSIONS}

In conclusion, the rate of bladder cancer survival in Hispanics and APIs appears similar to that of whites. However, DSS disparities persist between whites and blacks and are not fully explained by differences in disease presentation and receipt of treatment. Although stage at diagnosis and DSS improved over time in all racial/ethnic groups, blacks were consistently more likely to die from their disease. Factors that may explain survival disparities include variation in quality and timing of primary therapy, surveillance after primary therapy, treatment of recurrent disease, comorbidity and tumor biology. Further investigation of the role of these factors is needed to better understand and eliminate the persistent disparities in bladder cancer outcomes.

\section{Acknowledgments}

This research was supported by The Sidney Kimmel Center for Prostate and Urologic Cancers at MSKCC. Dr. Lowrance is a research fellow in urologic oncology supported by NIH grant T32-CA82088 and by a gift from the Tina and Richard V. Carolan Foundation.

\section{REFERENCES}

1. Aben KK, Kiemeney LA. Epidemiology of bladder cancer. Eur Urol. 1999; 36:660-672. [PubMed: 10559623]

2. Konety, BR.; Joyce, GF.; Wise, M. Litwin, MS.; Saigal, CS. Urologic Diseases in America. Washington, DC: US Department of Health and Human Services, National Institutes of Health, National Institute of Diabetes and Digestive and Kidney Diseases; 2007. Bladder and upper tract urothelial cancer; p. 225-279.

3. Madeb R, Messing EM. Gender, racial and age differences in bladder cancer incidence and mortality. Urol Oncol. 2004; 22:86-92. [PubMed: 15082003]

4. Lee CT, Dunn RL, Williams C, et al. Racial disparity in bladder cancer: trends in tumor presentation at diagnosis. J Urol. 2006; 176:927-933. discussion 933-4. [PubMed: 16890657]

5. Prout GR Jr, Wesley MN, Greenberg RS, et al. Bladder cancer: race differences in extent of disease at diagnosis. Cancer. 2000; 89:1349-1358. [PubMed: 11002231]

6. Prout GR Jr, Wesley MN, McCarron PG, et al. Survival experience of black patients and white patients with bladder carcinoma. Cancer. 2004; 100:621-630. [PubMed: 14745881] 
7. Underwood W 3rd, Dunn RL, Williams C, et al. Gender and geographic influence on the racial disparity in bladder cancer mortality in the US. J Am Coll Surg. 2006; 202:284-290. [PubMed: 16427554]

8. Ries, LAG.; Melbert, D.; Krapcho, M. SEER Cancer Statistics Review, 1975-2005. Bethesda, MD: National Cancer Institute; 2008.

9. Ghosh C. A national health agenda for Asian Americans and Pacific Islanders. Jama. 2010; 304:1381-1382. [PubMed: 20858884]

10. Ghosh C. Healthy People 2010 and Asian Americans/Pacific Islanders: defining a baseline of information. Am J Public Health. 2003; 93:2093-2098. [PubMed: 14652340]

11. Scosyrev E, Noyes K, Feng C, et al. Sex and racial differences in bladder cancer presentation and mortality in the US. Cancer. 2009; 115:68-74. [PubMed: 19072984]

12. Schultz PK, Herr HW, Zhang ZF, et al. Neoadjuvant chemotherapy for invasive bladder cancer: prognostic factors for survival of patients treated with M-VAC with 5-year follow-up. J Clin Oncol. 1994; 12:1394-1401. [PubMed: 8021730]

13. Stein JP, Lieskovsky G, Cote R, et al. Radical cystectomy in the treatment of invasive bladder cancer: long-term results in 1,054 patients. J Clin Oncol. 2001; 19:666-675. [PubMed: 11157016]

14. Gore JL, Kwan L, Saigal CS, et al. Marriage and mortality in bladder carcinoma. Cancer. 2005; 104:1188-1194. [PubMed: 16078264]

15. Krongrad A, Lai H, Burke MA, et al. Marriage and mortality in prostate cancer. J Urol. 1996; 156:1696-1670. [PubMed: 8863573]

16. Centers for Disease Control and Prevention: Prevalence of cigarette use among $14 \mathrm{racial} / \mathrm{ethnic}$ populations--United States, 1999-2001. MMWR Morb Mortal Wkly Rep. 2004; 53:49-52. [PubMed: 14749612]

17. Pamuk, E.; Makuc, D.; Heck, K., et al. Socioeconomic Status and Health Chartbook. Health, United States, 1998. Hyattsville, MD: US Department of Health and Human Services, National Center for Health Statistics; 1998.

18. Aveyard P, Adab P, Cheng KK, et al. Does smoking status influence the prognosis of bladder cancer? A systematic review. BJU Int. 2002; 90:228-239. [PubMed: 12133057]

19. Konety BR, Joslyn SA. Factors influencing aggressive therapy for bladder cancer: an analysis of data from the SEER program. J Urol. 2003; 170:1765-1771. [PubMed: 14532772]

20. Hankey BF, Myers MH. Black/white differences in bladder cancer patient survival. J Chronic Dis. 1987; 40:65-73. [PubMed: 3805235]

21. Mayer WJ, McWhorter WP. Black/white differences in non-treatment of bladder cancer patients and implications for survival. Am J Public Health. 1989; 79:772-775. [PubMed: 2729474]

22. Hollenbeck BK, Dunn RL, Ye Z, et al. Racial differences in treatment and outcomes among patients with early stage bladder cancer. Cancer. 2010; 116:50-56. [PubMed: 19877112]

23. Schrag D, Mitra N, Xu F, et al. Cystectomy for muscle-invasive bladder cancer: patterns and outcomes of care in the Medicare population. Urology. 2005; 65:1118-1125. [PubMed: 15922428]

24. Konety BR, Allareddy V, Carroll PR. Factors affecting outcomes after radical cystectomy in African Americans. Cancer. 2007; 109:542-548. [PubMed: 17200961]

25. Taub DA, Hollenbeck BK, Cooper KL, et al. Racial disparities in resource utilization for cystectomy. Urology. 2006; 67:288-293. [PubMed: 16442599]

26. Begg CB, Cramer LD, Hoskins WJ, et al. Impact of hospital volume on operative mortality for major cancer surgery. Jama. 1998; 280:1747-1751. [PubMed: 9842949]

27. Konety BR, Dhawan V, Allareddy V, et al. Impact of hospital and surgeon volume on in-hospital mortality from radical cystectomy: data from the health care utilization project. J Urol. 2005; 173:1695-1700. [PubMed: 15821560]

28. Schrag D, Hsieh LJ, Rabbani F, et al. Adherence to surveillance among patients with superficial bladder cancer. J Natl Cancer Inst. 2003; 95:588-597. [PubMed: 12697851]

29. Miller DC, Taub DA, Dunn RL, et al. The impact of co-morbid disease on cancer control and survival following radical cystectomy. J Urol. 2003; 169:105-109. [PubMed: 12478114]

30. Bradley CJ, Given CW, Roberts C. Race, socioeconomic status, and breast cancer treatment and survival. J Natl Cancer Inst. 2002; 94:490-496. [PubMed: 11929949] 


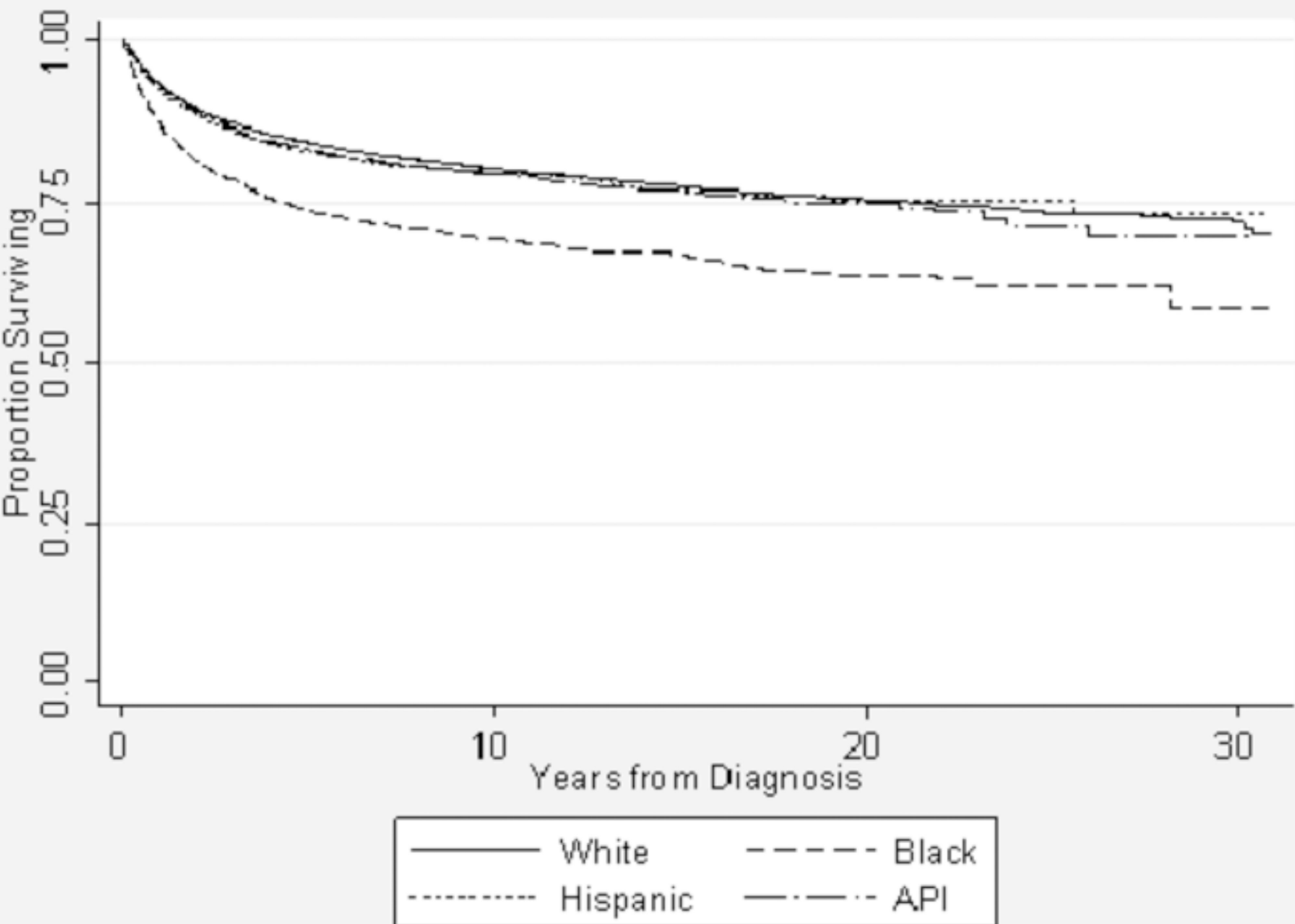

FIG. 1.

Disease-specific survival by ethnicity for Surveillance, Epidemiology and End Results (SEER) bladder cancer patients diagnosed 1975 - 2005. 
TABLE 1

Patient characteristics stratified by ethnicity for SEER bladder cancer patients diagnosed 1975-2005

\begin{tabular}{|c|c|c|c|c|}
\hline & $\begin{array}{c}\text { White } \\
\mathbf{n}=\mathbf{1 6 3 , 9 7 3}\end{array}$ & $\begin{array}{c}\text { Black } \\
\mathbf{n}=7,731\end{array}$ & $\begin{array}{c}\text { Hispanic } \\
n=7,364\end{array}$ & $\underset{\mathbf{n}=5,934}{\text { API }}$ \\
\hline & $\mathrm{n}(\%)$ & n $(\%)$ & n $(\%)$ & $\mathrm{n}(\%)$ \\
\hline \multicolumn{5}{|c|}{ Age at diagnosis, years } \\
\hline$<50$ & $9,522(6)$ & $624(8)$ & $727(10)$ & $387(6)$ \\
\hline $50-59$ & $20,888(13)$ & $1,202(16)$ & $1,074(15)$ & $723(12)$ \\
\hline $60-69$ & $41,343(25)$ & $2,030(26)$ & $1,933(26)$ & $1,423(24)$ \\
\hline $70-79$ & $54,771(33)$ & $2,416(31)$ & $2,235(30)$ & $2,047(34)$ \\
\hline$\geq 80$ & $37,449(23)$ & $1,459(19)$ & $1,395(19)$ & $1,354(23)$ \\
\hline \multicolumn{5}{|l|}{ Gender } \\
\hline Male & $123,727(75)$ & $5,149(67)$ & $5,456(74)$ & $4,472(75)$ \\
\hline Female & $40,246(25)$ & $2,582(33)$ & $1,908(26)$ & $1,462(25)$ \\
\hline \multicolumn{5}{|l|}{ Marital status } \\
\hline Married & $107,565(65)$ & $3,591(47)$ & $4,581(62)$ & $4,166(70)$ \\
\hline Not married & $50,388(31)$ & $3,800(49)$ & $2,537(34)$ & $1,601(27)$ \\
\hline Unknown & $6,020(4)$ & $340(4)$ & $246(3)$ & $167(3)$ \\
\hline \multicolumn{5}{|c|}{ Median income (quartiles) } \\
\hline Highest quartile & $42,011(26)$ & $1,379(18)$ & $1,772(24)$ & $1,193(20)$ \\
\hline $3^{\text {rd }}$ quartile & $42,398(26)$ & $1,691(22)$ & $1,042(14)$ & $2,930(49)$ \\
\hline $2^{\text {nd }}$ quartile & $38,017(23)$ & $1,793(23)$ & $2,994(41)$ & $1,584(27)$ \\
\hline Lowest quartile & $41,541(25)$ & $2,868(37)$ & $1,555(21)$ & $226(4)$ \\
\hline \multicolumn{5}{|l|}{ Urban residence } \\
\hline Metro & $142,572(87)$ & 7,491 (97) & $6,853(93)$ & $5,761(97)$ \\
\hline Non-metro & $21,395(13)$ & $240(3)$ & $510(7)$ & $172(3)$ \\
\hline \multicolumn{5}{|l|}{ Year of diagnosis } \\
\hline 1975-1979 & $12,734(8)$ & $479(6)$ & $251(3)$ & $257(4)$ \\
\hline 1980-1989 & $32,373(20)$ & $1,314(17)$ & $743(10)$ & $838(14)$ \\
\hline 1990-1999 & $48,722(30)$ & $2,372(31)$ & $2,208(30)$ & $2,142(36)$ \\
\hline 2000-2005 & $70,144(43)$ & $3,566(46)$ & $4,162(57)$ & $2,697(45)$ \\
\hline \multicolumn{5}{|l|}{ Geographic area } \\
\hline Northeast & $33,028(20)$ & $1,030(13)$ & $1,004(14)$ & $200(3)$ \\
\hline South & $14,480(9)$ & $1,623(21)$ & $162(2)$ & $75(1)$ \\
\hline Midwest & $38,465(23)$ & $2,262(29)$ & $222(3)$ & $88(1)$ \\
\hline West & $78,000(48)$ & $2,816(37)$ & $5,976(81)$ & $5,571(94)$ \\
\hline \multicolumn{5}{|l|}{ Pathologic stage } \\
\hline Localized & $129,933(79)$ & $5,329(69)$ & $5,629(76)$ & $4,567(77)$ \\
\hline
\end{tabular}




\begin{tabular}{|l|c|c|c|c|}
\hline & $\begin{array}{c}\text { White } \\
\mathbf{n = 1 6 3 , 9 7 3}\end{array}$ & $\begin{array}{c}\text { Black } \\
\mathbf{n = 7 , 7 3 1}\end{array}$ & $\begin{array}{c}\text { Hispanic } \\
\mathbf{n = 7 , 3 6 4}\end{array}$ & $\begin{array}{c}\text { API } \\
\mathbf{n = 5 , 9 3 4}\end{array}$ \\
\hline & $\mathbf{n}(\boldsymbol{\%})$ & $\mathbf{n}(\boldsymbol{\%})$ & $\mathbf{n}(\boldsymbol{\%})$ & $\mathbf{n}(\mathbf{\%})$ \\
\hline Regional & $29,703(18)$ & $1,947(25)$ & $1,444(20)$ & $1,147(19)$ \\
Distant & $4,337(3)$ & $455(6)$ & $291(4)$ & $220(4)$ \\
\hline Pathologic grade & & & & \\
Well differentiated & $28,484(17)$ & $1,062(14)$ & $1,224(16)$ & $833(14)$ \\
Moderately differentiated & $60,445(37)$ & $2,396(31)$ & $2,705(37)$ & $1,981(33)$ \\
Poorly differentiated & $44,531(27)$ & $2,482(32)$ & $1,960(27)$ & $1,812(31)$ \\
Undifferentiated & $18,932(12)$ & $1,132(15)$ & $987(13)$ & $880(15)$ \\
Unknown & $11,581(7)$ & $659(8)$ & $488(7)$ & $428(7)$ \\
\hline Primary treatment & & & & \\
Surgery only & $146,785(91)$ & $6,363(84)$ & $6,643(91)$ & $5,277(89)$ \\
Radiation only & $640(1)$ & $99(1)$ & $31(1)$ & $48(1)$ \\
Surgery + radiation & $8,738(5)$ & $626(8)$ & $314(4)$ & $351(6)$ \\
Other & $5,614(3)$ & $505(7)$ & $326(4)$ & $224(4)$ \\
\hline
\end{tabular}

$P$-values are $<.001$ for all characteristics.

SEER: Surveillance, Epidemiology and End Results cancer registry; API: Asian/Pacific Islander.

'Other' treatment included strategies that did not involve surgery or radiation therapy, such as observation or systemic chemotherapy. 
TABLE 2

5-Year disease-specific survival in SEER bladder cancer patients diagnosed 1975-2005

\begin{tabular}{|l|c|c|c|c|}
\hline & \multicolumn{4}{|c|}{ \% 5-Year Disease-Specific Survival } \\
\cline { 2 - 5 } & White & Black & Hispanic & API \\
\hline All & 82.8 & 70.2 & 80.7 & 81.9 \\
\hline Pathologic stage & & & & \\
Localized & 92.1 & 85.9 & 91.6 & 92.7 \\
Regional & 50.3 & 41.5 & 49.7 & 51.3 \\
Distant & 8.4 & 7.4 & 7.5 & 8.2 \\
\hline Pathologic grade & & & & \\
Well differentiated & 97.3 & 94.2 & 97.6 & 97.7 \\
Moderately differentiated & 92.7 & 86.7 & 92.2 & 93.0 \\
Poorly differentiated & 67.7 & 51.9 & 62.4 & 70.6 \\
Undifferentiated & 58.1 & 48.2 & 57.6 & 60.4 \\
\hline
\end{tabular}

SEER: Surveillance, Epidemiology and End Results cancer registry; API: Asian/Pacific Islander. 
TABLE 3

Multivariable analysis of cancer-specific death for SEER bladder cancer patients diagnosed 1975 - 2005

\begin{tabular}{|c|c|c|}
\hline Variable & HR $(95 \%$ CI $)$ & $P$-value \\
\hline Age at diagnosis, years & & $<0.0001$ \\
\hline$<50$ & Referent & \\
\hline $50-59$ & $1.36(1.25-1.47)$ & \\
\hline $60-69$ & $1.75(1.63-1.89)$ & \\
\hline $70-79$ & $2.34(2.17-2.51)$ & \\
\hline$\geq 80$ & $3.78(3.51-4.07)$ & \\
\hline Ethnicity & & $<0.0001$ \\
\hline White & Referent & \\
\hline Black & $1.29(1.24-1.36)$ & \\
\hline Hispanic & $1.03(0.97-1.10)$ & \\
\hline API & $0.95(0.89-1.02)$ & \\
\hline Gender & & $<0.0001$ \\
\hline Male & Referent & \\
\hline Female & $1.06(1.03-1.09)$ & \\
\hline Marital status & & $<0.0001$ \\
\hline Married & Referent & \\
\hline Not married & $1.26(1.23-1.29)$ & \\
\hline Median income & & $<0.0001$ \\
\hline Highest quartile & Referent & \\
\hline $3^{\text {rd }}$ quartile & $1.02(0.98-1.05)$ & \\
\hline $2^{\text {nd }}$ quartile & $1.10(1.06-1.14)$ & \\
\hline Lowest quartile & $1.10(1.05-1.14)$ & \\
\hline Urban residence & & 0.02 \\
\hline Metro & Referent & \\
\hline Non-Metro & $0.95(0.91-0.99)$ & \\
\hline Geographic area & & $<0.0001$ \\
\hline Northeast & Referent & \\
\hline South & $1.02(0.97-1.07)$ & \\
\hline Midwest & $1.01(0.96-1.05)$ & \\
\hline West & $0.95(0.91-0.98)$ & \\
\hline Pathologic stage & & $<0.0001$ \\
\hline Localized & Referent & \\
\hline Regional & $4.07(3.95-4.19)$ & \\
\hline Distant & $15.97(15.30-16.67)$ & \\
\hline Pathologic grade & & $<0.0001$ \\
\hline
\end{tabular}




\begin{tabular}{|l|l|l|}
\hline Variable & HR $(\mathbf{9 5 \%}$ CI) & P-value \\
\hline Well differentiated & Referent & \\
Moderately differentiated & $2.24(2.09-2.40)$ & \\
Poorly differentiated & $5.21(4.87-5.58)$ & \\
Undifferentiated & $5.90(5.49-6.33)$ & \\
Unknown & $3.59(3.32-3.88)$ & \\
\hline Year of diagnosis & & $<0.0001$ \\
$1975-1979$ & Referent & \\
$1980-1989$ & $0.83(0.80-0.87)$ & \\
$1990-1999$ & $0.74(0.71-0.77)$ & \\
2000-2005 & $0.73(0.70-0.77)$ & \\
\hline Primary treatment & & $<0.0001$ \\
Surgery & Referent & \\
Surgery + radiation & $1.37(1.32-1.41)$ & \\
Radiation only & $2.06(1.89-2.24)$ & \\
Other & $2.11(1.99-2.22)$ & \\
\hline
\end{tabular}

SEER: Surveillance, Epidemiology, and End Results cancer registry; API: Asian/Pacific Islander. 